\title{
Are patients truly informed? A retrospective chart review of the documentation of informed consent in laparoscopic cholecystectomy
}

\author{
Erin Williams, MD \\ Raj Selvam, MD \\ Wilma Hopman, MA \\ Sulaiman Nanji, MD, PhD
}

Presented at the Canadian Surgery Forum, Sept. 5-7, 2019, Montréal, Que.

Accepted Oct. 5, 2020

\section{Correspondence to:}

S. Nanji

Department of Surgery

Queen's University

76 Stuart St

Kingston ON K7L 2V7

sulaiman.nanji@kingstonhsc.ca

DOI: $10.1503 /$ cjs.004120

\begin{abstract}
Background: Research on informed consent (IC) has traditionally focused on the documentation of the discussion with patients of potential complications. We sought to examine the completeness of documentation for all elements of IC for laparoscopic cholecystectomy (LC): potential complications, alternatives to LC and details of the procedure. Differences in the documentation of IC for elective and emergent LC were examined.
\end{abstract}

Methods: A retrospective chart review of patients undergoing LC at our institution between 2015 and 2017 was performed. Completeness of documentation was defined as documentation of all 3 elements of IC in the clinic note, the operating room note or the consent form itself. Data were analyzed descriptively. We compared documention for emergent and elective cases as well as documentation by residents and attending physicians using $t$ tests.

Results: A total of 270 patients were included in the analysis. Only 5 (2\%) had complete documentation of all elements of IC. Documentation of potential complications was noted in 232 cases $(86 \%)$, of which 58 (25\%) were elective and $174(75 \%)$ were emergent. Details were noted in $28(10 \%)$ cases, of which $21(75 \%)$ were elective and $7(25 \%)$ were emergent. Alternatives were documented the least frequently: they were documented in 23 cases (9\%), of which $20(87 \%)$ were elective and $3(13 \%)$ were emergent. Residents performed better than attending physicians in documenting IC discussions in clinic notes and on consent forms, but not in operating room notes.

Conclusion: Documentation of the elements of IC for LC was poor. Potential complications were the most frequently documented element of IC; alternatives and details were often omitted. Future studies comparing audiotaped IC conversations with the documentation of IC are warranted. The use of procedure-specific consent forms for LC may facilitate documentation.

Contexte : La recherche sur le consentement éclairé (CÉ) s'est longtemps intéressée surtout à la consignation du contenu des discussions avec les patients au sujet des complications potentielles. Nous avons voulu examiner l'exhaustivité de la consignation de tous les éléments du CÉ pour la cholécystectomie laparoscopique (CL) : complications potentielles, solutions de rechange à la CL et détails de l'intervention. Nous avons observé des différences dans la consignation des éléments du CÉ pour la CL urgente et non urgente.

Méthodes : Nous avons procédé à un examen rétrospectif des dossiers de patients soumis à une CL dans notre établissement entre 2015 et 2017. La consignation au dossier était jugée complète lorsque les 3 éléments du CÉ étaient présents dans la note clinique, la note opératoire ou le formulaire de consentement lui-même. Nous avons effectué une analyse descriptive des données, et nous avons comparé la consignation des éléments pour les cas urgents et non urgents, effectuée par les résidents et les médecins traitants au moyen de tests $t$.

Résultats : Au total, 270 patients ont été inclus dans l'analyse. Tous les éléments du CÉ étaient adéquatement consignés pour seulement $5(2 \%)$ d'entre eux. Les complications potentielles ont été consignées dans 232 cas (86\%), dont 58 (25\%) étaient non urgents et 174 (75\%) étaient urgents. Les détails de l'intervention ont été notés dans 28 cas (10\%), dont $21(75 \%)$ étaient non urgents et 7 (25\%) étaient urgents. Ce sont les solutions de rechange qui ont été le moins souvent consignées : elles ont été notées dans 23 cas (9\%), dont 20 (87\%) étaient non urgents et 3 (13\%) étaient urgents. Les résidents ont mieux fait que les médecins traitants pour ce qui est de consigner les discussions sur le CÉ dans les notes cliniques et les formulaires de CÉ, mais non dans les notes opératoires.

Conclusion : La consignation des éléments du CÉ pour la CL a été faible. Les complications potentielles ont été l'élément du CÉ le plus souvent consigné au dossier; les solutions de rechange et les détails de l'intervention ont souvent été omis. Il faudra procéder à d'autres études pour comparer le contenu des discussions sur le CÉ enregistrées sur bande audio et sa consignation. L'utilisation de formulaires de CÉ spécifiques aux interventions pourrait faciliter la consignation de leurs éléments. 
$\mathbf{T}$ he concept of informed consent (IC) and its elements are well established, but little research has been devoted to examining the completeness of documentation of this critically important medical practice. The Canadian Medical Protective Association (CMPA) defines 3 aspects of IC: it must be voluntary, the patient must have the capacity to consent and the patient must be informed of the proposed treatment in a way that a reasonable person would understand. ${ }^{1}$ Essential elements of the IC discussion include details about the procedure, potential complications and proposed alternatives. It is expected that "along with a signed consent form, there should be supplemental documentation of details of the consent discussion in the patient chart or on the physical consent form itself." 1

According to the Canadian Medical Association (CMA) in $2016,65 \%$ of all medical-legal cases involving inadequacy of informed consent involved surgical procedures, and $79 \%$ of these had unfavourable outcomes. ${ }^{2}$ In 2017 the CMPA reported that there were 423 medical-legal cases regarding laparoscopic procedures, with one of the most common procedures being the laparoscopic cholecystectomy (LC). ${ }^{3}$ Of these, $29 \%$ pertained to issues in preoperative care including inadequacies with the consent process. Where consent was the issue, half involved either poor documentation of the consent discussion or complete absence of documentation.

Although proper documentation of complications in IC is imperative, we aimed to outline the documentation of all elements of IC, including details of the procedure and discussion of surgical alternatives in both emergent and elective populations. The purpose of our study was to investigate the rate of successful complete documentation of all elements of IC for LC at our institution. Differences in documentation of the elements of IC among residents and attending surgeons as well as elective and emergent LCs were examined to help identify barriers to obtaining comprehensive IC, with the aim to improve future documentation of a common general surgery procedure.

\section{Methods}

\section{Study design}

We conducted a retrospective chart review of all patients who underwent LC at either of 2 academic hospitals of the Kingston Health Sciences Centre between 2015 and 2017. Ethics approval was obtained from the Health Sciences Research Ethics Board at the Kingston Health Sciences Centre.

\section{Data collection}

Patients who underwent LC were identified by electronic internal coding by a research nurse using the code applicable for LC. Demographic data were collected including age and sex, along with information on whether the procedure was emergent or elective. Completeness of the IC discussion was determined by documentation of 3 key elements of IC: details of the procedure, alternatives to the procedure and potential complications. If any of these elements were missing, documentation was considered incomplete. Three of the most common sites for documentation of the IC discussion at our institution were examined by an independent reviewer through the hospital's online charting system; the clinic note, the operating room (OR) note and the physical consent form. Documentation of discussion of the details of the procedure was considered complete if there was documentation that "details were discussed" or "details were described" or there was specific documentation of the nature of the procedure itself. Documentation of discussion of alternatives to the procedure was considered complete if there was documentation of 1 or more nonsurgical options. Documentation of discussion of potential complications of the procedure was considered complete if there was documentation of 1 or more complications, which included conversion to open cholecystectomy. If an element of informed consent was documented in multiple places in the patient chart, it was recorded in each site but counted only once per case. Differences in documentation of IC between residents and attendings were analyzed when possible. Capacity to consent was omitted as this is often subjective and is determined using clinical judgment, and it was assumed to be present in all cases.

\section{Statistical analysis}

Deidentified data were entered into an Excel file designed for the study and then analyzed using IBM SPSS version 24.0 for Windows. We initially analyzed the data descriptively, including calculating means and standard deviations for continuous data and frequencies and percentages for categorical data. Subgroup analyses between emergent and elective cases as well as resident versus attending documentation were established a priori and compared on all variables using $t$ tests for continuous data and the Pearson $\chi^{2}$ test or Fisher exact test for categorical data. A $p$ value of 0.05 was used as the level of statistical significance, and no adjustments were made for multiple comparisons.

\section{Results}

\section{Patient characteristics}

A total of 271 patients underwent LC between 2015 and 2017 at our institution. One patient did not have documentation of the surgical procedure and was omitted, yielding 270 patients for analysis. Of these, 71 (26\%) underwent elective LC and 199 (74\%) underwent 
emergent LC. Eighty-three (31\%) were male and 187 $(69 \%)$ were female; there were equal numbers of elective and emergent cases. The mean age of patients was 51.6 years; there was no difference between elective and emergent cases (Table 1).

\section{Documentation of informed consent}

In the entire cohort, only 5 (2\%) had complete documentation of all elements of IC, all in elective cases. Table 2 and Table 3 show the frequency of documentation of the elements of IC. Alternatives to LC was the most poorly

Table 1. Demographic characteristics of 270 patients
undergoing elective or emergent laparoscopic
cholecystectomy

Table 2. Elements of informed consent documented for 270 patients undergoing elective or emergent laparoscopic cholecystectomy

\begin{tabular}{|lccc|} 
& \multicolumn{3}{c|}{ Procedure; no. (\%) of patients } \\
\cline { 2 - 4 } Element & $\begin{array}{c}\text { Total } \\
n=270\end{array}$ & $\begin{array}{c}\text { Elective } \\
n=71\end{array}$ & $\begin{array}{c}\text { Emergent } \\
n=199\end{array}$ \\
\hline Potential complications & $232(86)$ & $58(25)$ & $174(75)$ \\
\hline Procedure details & $28(10)$ & $21(75)$ & $7(25)$ \\
\hline $\begin{array}{l}\text { Alternatives to surgical } \\
\text { procedure }\end{array}$ & $23(9)$ & $20(87)$ & $3(13)$ \\
\hline
\end{tabular}

Table 3. Frequency of documentation of informed consent for $\mathbf{2 7 0}$ patients undergoing elective or emergent laparoscopic cholecystectomy

\begin{tabular}{|lcc|} 
& \multicolumn{2}{c|}{ Procedure; no. (\%) of patients } \\
\cline { 2 - 3 } Element & $\begin{array}{c}\text { Elective } \\
n=71\end{array}$ & $\begin{array}{c}\text { Emergent } \\
n=199\end{array}$ \\
\hline Potential complications & \\
\hline Clinic note & $53(75)$ & $2(1)$ \\
\hline Operating room note & $17(24)$ & $56(28)$ \\
\hline Consent form & $51(72)$ & $182(91)$ \\
\hline Procedure details & & \\
\hline Clinic note & $13(18)$ & $0(0)$ \\
\hline Operating room note & $11(15)$ & $7(4)$ \\
\hline Consent form & $0(0)$ & $0(0)$ \\
\hline Alternatives to surgical procedure & & \\
\hline Clinic note & $16(23)$ & $0(0)$ \\
\hline Operating room note & $5(7)$ & $3(2)$ \\
\hline Consent form & $0(0)$ & $0(0)$ \\
\hline
\end{tabular}

documented element; this element was documented in $23(9 \%)$ cases, of which $20(87 \%)$ were elective and $3(13 \%)$ were emergent. More specifically, alternatives were documented in 16 elective clinic notes $(23 \%$ of 71 elective cases), 3 emergent OR notes ( $2 \%$ of 199 emergent cases) and 5 elective OR notes (7\% of elective cases); there was no documentation of alternatives on consent forms.

Details of the procedure were noted in $28(10 \%)$ cases, of which 21 (75\%) were elective and 7 (25\%) were emergent. Specifically, details were documented in 13 elective clinic notes (18\% of elective cases), 11 elective OR notes ( $15 \%$ of elective cases) and 7 emergent OR notes ( $4 \%$ of emergent cases); they were not noted on any consent forms.

Potential complications were the most frequently and consistently documented element of the IC discussion. They were noted in $232(86 \%)$ cases, of which $58(25 \%)$ were elective and $174(75 \%)$ were emergent. Complications were documented in 53 elective clinic notes $(75 \%$ of elective cases), 2 emergent clinic notes (1\% of emergent cases), 17 elective OR notes (24\% of elective cases), 56 emergent OR notes (28\% of emergent cases), 51 elective consent forms ( $72 \%$ of elective cases) and 182 emergent consent forms (91\% of emergent cases).

The most frequently documented potential complication was conversion to open surgery (259 cases), followed by bile duct injury ( 42 cases), bleeding ( 35 cases) and infection (32 cases). In 51 cases, complications were documented as a generic statement, such as "the complications were discussed" (Table 4). Actual complications of LC at our institution during this timeline are outlined in Table 5. Specifically, there were 4 conversions to open surgery $(2 \%), 3$ bowel injuries (1\%), 2 bile duct injuries (1\%) and 1 infection (0.4\%); there were no cases of bleeding.

\section{Comparison between residents and attendings}

Residents were noted to complete the majority of the consent forms (74\%). When we included all elements of the IC, we found that residents were better at documentation in clinic notes and on the physical consent form itself, whereas attending surgeons were better at documentation in OR notes (Table 6).

\section{Discussion}

The purpose of this study was to examine the rate of successful documentation of all elements of IC for LC in both the elective and emergent settings. Our results demonstrate that we are poor documenters of IC. Of the 270 cases reviewed, only $5(2 \%)$ had documentation of all elements of IC, with 265 (98\%) of cases having incomplete documentation.

Alternatives to surgical management were the most poorly documented element of informed consent: they 


\begin{tabular}{|c|c|c|c|c|}
\hline \multirow[b]{2}{*}{ Potential complication } & \multirow[b]{2}{*}{$\begin{array}{l}\text { Total no. of } \\
\text { patients }\end{array}$} & \multicolumn{3}{|c|}{ Document; no. (\%) of patients } \\
\hline & & $\begin{array}{c}\text { Clinic note } \\
n=61\end{array}$ & $\begin{array}{l}\text { Operating room note } \\
\qquad n=269\end{array}$ & $\begin{array}{c}\text { Consent form } \\
\quad n=269\end{array}$ \\
\hline Conversion to open surgery & 259 & $10(16)$ & $16(6)$ & $233(87)$ \\
\hline Bile duct injury & 42 & $25(41)$ & $17(6)$ & $0(0)$ \\
\hline Bleeding & 35 & $24(39)$ & $11(4)$ & $0(0)$ \\
\hline Infection & 32 & $23(36)$ & $9(3)$ & $0(0)$ \\
\hline Bowel injury & 17 & $13(21)$ & $4(2)$ & $0(0)$ \\
\hline Bile leak & 12 & $11(18)$ & $1(4)$ & $0(0)$ \\
\hline Hernia & 4 & $2(3)$ & $2(1)$ & $0(0)$ \\
\hline Subtotal cholecystectomy & 0 & $0(0)$ & $0(0)$ & $0(0)$ \\
\hline Generic statement:"Complications discussed" & 51 & $20(33)$ & $31(12)$ & $0(0)$ \\
\hline
\end{tabular}

Table 5. Actual rates of complications among patients undergoing elective or emergent laparoscopic cholecystectomy between 2015 and 2017

\begin{tabular}{|lccc|} 
& \multicolumn{3}{c|}{ Type of procedure; no. (\%) of patients } \\
\cline { 2 - 4 } Complication & $\begin{array}{c}\text { Elective } \\
n=71\end{array}$ & $\begin{array}{c}\text { Emergent } \\
n=199\end{array}$ & $\begin{array}{c}\text { Total } \\
n=270\end{array}$ \\
\hline $\begin{array}{l}\text { Conversion to open } \\
\text { surgery }\end{array}$ & $1(0.4)$ & $3(1)$ & $4(2)$ \\
\hline Bowel injury & $0(0)$ & $3(1)$ & $3(1)$ \\
\hline $\begin{array}{l}\text { Subtotal } \\
\text { cholecystectomy }\end{array}$ & $1(0.4)$ & $1(0.4)$ & $2(1)$ \\
\hline Bile duct injury & $1(0.4)$ & $1(0.4)$ & $2(1)$ \\
\hline Wound infection & 0 & $1(0.4)$ & $1(0.4)$ \\
\hline Total & $2(3)$ & $9(5)$ & $11(4)$ \\
\hline
\end{tabular}

Table 6. Documentation of elements of informed consent for patients undergoing laparoscopic cholecystectomy by residents and attending physicians

\begin{tabular}{|c|c|c|c|}
\hline \multirow[b]{2}{*}{ Element } & \multicolumn{2}{|c|}{$\begin{array}{l}\text { Physician type; no. (\%) } \\
\text { of patients }\end{array}$} & \multirow[b]{2}{*}{$p$ value } \\
\hline & Residents & $\begin{array}{l}\text { Attending } \\
\text { physicians }\end{array}$ & \\
\hline \multicolumn{4}{|l|}{ Clinic note $(n=61)$} \\
\hline Potential complications & $30(49)$ & $9(15)$ & 0.09 \\
\hline Procedure details & $9(15)$ & $1(2)$ & 0.42 \\
\hline $\begin{array}{l}\text { Alternatives to surgical } \\
\text { procedure }\end{array}$ & $10(16)$ & $4(31)$ & 0.72 \\
\hline \multicolumn{4}{|l|}{ Consent form $(n=269)$} \\
\hline Potential complications & $190(71)$ & $38(14)$ & $<0.001$ \\
\hline Details & $0(0)$ & $0(0)$ & NA \\
\hline $\begin{array}{l}\text { Alternatives to surgical } \\
\text { procedure }\end{array}$ & $0(0)$ & $0(0)$ & NA \\
\hline \multicolumn{4}{|c|}{ Operating room note $(n=269)$} \\
\hline Potential complications & $33(12)$ & $40(15)$ & $<0.001$ \\
\hline Procedure details & $5(2)$ & $13(5)$ & $<0.001$ \\
\hline $\begin{array}{l}\text { Alternatives to surgical } \\
\text { procedure }\end{array}$ & $4(1)$ & $4(1)$ & 0.35 \\
\hline
\end{tabular}

were documented in only $23(9 \%)$ of cases, of which $20(87 \%)$ were elective and $3(13 \%)$ were emergent. Details of the procedure were documented in only 28 $(10 \%)$ cases, of which $21(75 \%)$ were elective and $7(25 \%)$ were emergent. In an era of patient autonomy, it is just as important to describe the procedure and present nonsurgical management options as it is to relay potential complications. One explanation for this finding could be that surgeons and trainees do not feel that patients want to be presented with alternatives or details when discussing LC. A recent study examined patients' views on elements they perceived to be of importance in IC by asking them to complete a postprocedure survey after they underwent LC or a laparoscopic hernia repair. ${ }^{4}$ Results of the survey showed that $65.5 \%$ of patients thought that it was important to disclose details of the procedure, while $58.5 \%$ wanted to know the consequences of not having the procedure or alternatives. ${ }^{4}$ This would suggest that patients would prefer to know both the details of LC and alternatives to the procedure, and we are not meeting these needs if we either omit this discussion or do not document it.

It should also be acknowledged that surgeons and surgical trainees have an innate bias toward surgical management, potentially contributing to poor discussion of alternatives. In the emergent setting, it is perhaps understandable that alternatives are not explored, as early LC is the standard of care for acute cholecystitis or intractable biliary colic. ${ }^{5}$ Therefore, it would be challenging to present a nonoperative option to suitable surgical candidates. In the elective setting, patients often present to clinic having already completed the necessary investigations and attempted lifestyle modifications. They commonly present with an expectation that they will undergo surgery, and likewise there is an innate bias from the surgical team that surgery may be their only choice. One way to mitigate this bias could be to adopt a shared decision-making model, a unique concept that acknowledges bias 
toward surgical management. ${ }^{6}$ It is a communication process wherein the provider shares all relevant treatment risks, benefits and alternatives, the patient shares their personal values and together they make a mutual decision that incorporates these components. Aligning the personal preferences and expectations of the patient with the treatment decision has been shown not only to strengthen the therapeutic physicianpatient relationship, but also to be a protective factor medico-legally. ${ }^{6}$

Discussion of potential complications of LC was the element that was most consistently documented: it was documented in $232(86 \%)$ cases, of which $58(25 \%)$ were elective and 174 (75\%) were emergent. Fear of litigation may have contributed to the higher rate of documentation of complications compared with the rates of documentation of details and alternatives. Interestingly, the actual rate of complications of LC at our institution during the timeframe of this study was low: $2(3 \%)$ in the elective setting and $9(5 \%)$ in the emergent setting. A single-centre retrospective study from the United Kingdom examining the documentation of complications of LC found that the complications that were most commonly outlined were bleeding $(99 \%)$, infection $(95 \%)$, conversion to open surgery $(90 \%)$, common bile duct injury ( $82 \%)$, bile leak (55\%) and retained stones $(20 \%) .{ }^{7}$ Although this study provided a review of the documentation of complications of LC, it did not examine the documentation of the details of the procedure or alternatives to surgery. It also focused on a purely elective study population.

In our study, the most frequently documented potential complication was conversion to open surgery, noted on 259 consent forms. Although this correlates with conversion to open surgery being the most common complication seen at our institution $(2 \%)$, it is challenging to determine whether practitioners simply write "laparoscopic \pm open" reflexively on consent forms or whether knowledge of local conversion rates makes them more prudent about documenting it. Another noteworthy issue is the frequency of documentation of generic statements such as "complications were discussed" or "the patient understood the risks of the procedure," without documentation of any specific details. The CMPA reviewed 50 cases of LC medicallegal cases in Canada between 2008 and 2012 and noted that $83 \%$ involved biliary tree complications, $23 \%$ intestinal injuries and $8 \%$ hemorrhagic injuries; half of the cases had adverse legal ramifications for the surgeon. ${ }^{8}$ Common factors contributing to adverse legal outcomes included delayed recognition of the injury and failure to utilize mechanisms intraoperatively to properly identify challenging anatomy. The main theme acknowledged in this report was "concerns in lack of informed consent," highlighting that "an informed consent discussion should not leave the patient with the impression that the LC is a minor procedure." ${ }^{8}$ Failure to outline specific substantial complications can lead to ambiguity in the IC discussion and potential legal ramifications for practitioners.

The discordance in documentation of complications versus the other elements of IC may be in part due to what is being taught to medical trainees. In 1 study, 155 students at a German medical school were given a lecture on the legal aspects of consent as well as specific information on 3 general surgery scenarios: acute appendicitis, LC and open hernia repair with mesh. ${ }^{9}$ They were also provided with a manual containing a consent form as well as specifics on the technical aspects of the procedures. They were then asked to obtain IC from a standardized patient. A checklist with essential IC components was established for each procedure and consisted of "introductory explanations (diagnosis/indication, choice of procedure, conversion to open, and extending the scope of the surgery), general complications (infection, positioning injury, hemorrhage, etc.) and specific complications (injury to neighbouring structures, bile duct, mesh infection, etc.)." 9 The results of this study are less important than the global message where teaching on competency of the IC process focused on obtaining check marks for stating complications. This disregards patient autonomy and decision-making by failing to ensure that the procedure is adequately explained and that nonsurgical options are presented.

It is imperative to teach surgical trainees how to obtain proper IC as they are the main front-line workers having these important discussions. Our data demonstrated that surgical residents completed $74 \%$ of all consent forms examined. A study from the University of Manitoba evaluated the attitudes of surgical trainees about obtaining IC, noting that we are not meeting these educational requirements. ${ }^{10}$ They found that almost $90 \%$ of surgical trainees felt they obtained IC while being insufficiently knowledgeable about the information required, and $31 \%$ indicated that IC occurs with some degree of ambivalence, identifying factors such as concern for being viewed as competent, time efficiency and concern about criticism from attending surgeons as contributing to inadequate IC. Multiple initiatives to improve the teaching of IC to residents have been explored in the literature; it has been acknowledged that teaching and evaluating bioethical principles in learners remains challenging. Robb and colleagues compared the effectiveness of an interactive seminar using a standardized patient with that of a traditional lecture-based seminar containing a clinical vignette, for teaching IC to surgical residents. Residents were randomly assigned to 1 of 2 groups. They were evaluated on obtaining IC for LC during a 10 -minute SP interview. ${ }^{11}$ Evaluation was based on a checklist that included all 3 elements of IC; 
however, an important additional element on the checklist was "creating an atmosphere that is conducive to asking questions" and "inviting patient to ask questions." 11 Although residents scored better after the traditional lecture-based scenario in knowledge- and performancebased measures, both groups scored poorly in "evaluation of patient understanding of the procedure, discussion of alternatives ... and exploring the potential impact of surgery on the patient's personal life."11 Although this study acknowledged all elements of IC, it mirrored a global message that IC training and education is still lacking a holistic approach.

Interestingly, although teaching of IC is focused mostly on trainees, our data demonstrated that residents provided better documentation of IC on consent forms and clinic notes, whereas attendings provided better documentation in OR notes. This may reflect the lack of continuity of surgical care, where often the resident who obtains IC is different from the resident who performs the operation, making it challenging to document an IC discussion in the OR note. These results also highlight the fact that inexperience and knowledge deficits among residents are not the only factors contributing to poor documentation, as attending surgeons are equally poor documenters. Targeted initiatives focused on training surgical attendings may also be beneficial.

Specific institutional barriers such as the use of a generic paper-based consent form at our hospitals may also have contributed to poor documentation of the IC process. Procedure-specific consent forms (PSCFs) has been implemented elsewhere in attempts to improve documentation and discussion of IC. St. John and colleagues conducted a pilot study in breast surgery comparing electronic PSCFs with approximately 61 handwritten consent forms, examining 3 domains (patient details, procedure details and patient signature). ${ }^{12}$ After the electronic PSCF was implemented, there were no domain failures among 29 consent forms on the electronic platform over a 6-week period. In an Australian study, patients undergoing elective LC were randomly assigned to receive either a standard consent form or a PSCF that outlined specific potential complications of LC. ${ }^{13}$ On the consent forms were additional lines that stated "other risks include" and "other options of treatment have been discussed with me." Although documentation of complications for those receiving PSCFs was noted to be better, there was no analysis of the documentation of details or alternatives to LC, and this study was conducted only for elective cases. Although the use of PSCFs appears to improve the documentation of complications, little attention has been paid to presenting surgical alternatives or details or ensuring that all patient concerns are answered. The addition of all elements into PSCFs and implementation of these forms in the emergent setting could improve IC discussion and its documentation.
We found that documentation of complications was better in the emergent setting than in the elective setting. This may correlate with surgeons' concern about increased morbidity for patients requiring emergency surgery compared with patients with a noninflamed gallbladder in the elective setting. A recent study from the University of Michigan retrospectively compared the morbidity and conversion to open surgery rates of 18106 elective and emergent cases. ${ }^{14}$ The conversion to open surgery rates were higher in the emergent groups $(17.5 \%$ v. $9.1 \%)$ but, interestingly, the rates of other outcomes of postoperative morbidity were not significantly higher. Similar trends were observed in complication rates at our centre. Conversion to open surgery occurred in $3(1 \%)$ emergent cases and $1(0.4 \%)$ elective case, and bowel injury occurred in $3(1 \%)$ emergent cases and 0 elective cases. This study highlights the trends we observed in our population. There is more diligence in documenting complications (particularly conversion to open surgery) in an emergent setting, where anatomic plains may be distorted and inflamed.

The 5 cases with complete documentation of all elements of IC were elective cases, probably because there is more time for discussion and documentation around IC in the elective setting. As the front-line team, surgical residents were also the main documenters of IC. House staff on a busy acute care surgical service face substantial time constraints that make proper documentation challenging. A study from the United Kingdom evaluated the IC practices of senior house officers (SHOs) involved in general surgery on-call rotas at 3 major teaching hospitals. ${ }^{15}$ SHOs were missing approximately $20 \%$ of morning ward rounds obtaining IC from patients. ${ }^{15}$ When they were asked how the process could be improved, they suggested modifying the IC form to improve efficiency and completing the IC discussion in clinic. Despite the known time constraints on a busy acute care surgical service, little research has focused on documentation in emergent settings.

Although we have identified that the documentation of IC is poor for $\mathrm{LC}$, it is challenging to determine whether adequate IC may have in fact occurred but was poorly documented. Etchells and colleagues attempted to categorize the completeness of IC in vascular surgery by audiotaping actual physician-patient conversations. The IC discussion was categorized into 3 levels of decisionmaking (basic, intermediate and complex). They assessed whether the patient's role in decision-making was discussed and whether the practitioner took into account the patient's preference, explained the procedure and rationale, the risks and benefits and the alternatives, assessed the patient's understanding and discussed uncertainty about the decision. ${ }^{16}$ There were 67 consultations that required more than 1 visit, and the multiple visits were all recorded. Significant improvement was noted in IC when the decision-making levels were compared among 
multiple visits, and $45 \%$ of consultations about major elective surgery were rated at a complex level of decisionmaking. Although this study provides an interesting perspective regarding the quality of IC discussions occurring in surgery, the authors did not compare the audiorecordings with the actual documentation of the discussion. Moreover, this study was limited to the elective surgical population, where there is the luxury of multiple clinic visits to discuss surgical options, making generalization to the emergent population challenging.

\section{Limitations}

Limitations to our study include its single-centre design, which makes it difficult to generalize our documentation of IC to other centres where more standardized or detailed documentation processes may be available. The documentation of IC was examined in the 3 most common sites (clinic notes, OR note and the consent form), and we acknowledge that there may be additional sources where the consent discussion may have been documented but that were not captured as part of the data collection in this study. Additionally, although documentation of the elements of IC was poor, this does not necessarily mean that practitioners had poor IC discussions with patients. Lastly, an important part of the IC discussion is providing adequate time to answer patient questions or concerns, and this was also not captured in the study.

\section{Conclusion}

The documentation of IC for LC at our institution was poor; documentation of IC elements was missing in most cases. Complications of IC were the most consistently documented IC element; documentation of discussion of alternatives to LC and details of the procedure was often missing. Research aimed at improving documentation of IC has focused on underscoring complications; although this is important, discussion of alternatives to surgical management and details of the procedure and efforts to ensure patient understanding should be equally emphasized. Future studies comparing audiotaped conversations of IC with actual documentation are warranted to determine the correlation between what is discussed and what is subsequently documented. Using PSCFs for LC, particularly in the emergent setting, may improve the documentation process.

Affiliations: From the Department of Surgery, Queen's University, Kingston, Ont. (Williams); the Department of Surgery, Kingston General Hospital Research Institute, Kingston, Ont. (Selvam); and the Kingston Health Sciences Centre, Kingston, Ont. (Hopman, Nanji).

Competing interests: None declared.

Contributors: E. Williams and S. Nanji designed the study. E. Williams, R. Selvam and S. Nanji acquired the data, which E. Williams, W. Hopman and S. Nanji analyzed. E. Williams and S. Nanji wrote the article, which E. Williams, R. Selvam, W. Hopman and S. Nanji critically reviewed. All authors gave final approval of the version to be published.

Content licence: This is an Open Access article distributed in accordance with the terms of the Creative Commons Attribution (CC BY-NC-ND 4.0) licence, which permits use, distribution and reproduction in any medium, provided that the original publication is properly cited, the use is noncommercial (i.e., research or educational use), and no modifications or adaptations are made. See: https://creativecommons.org/licenses/by-nc-nd/4.0/

\section{References}

1. Canadian Medical Protective Agency. Informed consent: more than a signature. Ottawa: Canadian Medical Protective Association. Available: www.cmpa-acpm.ca/serve/docs/ela/goodpracticesguide/ pages/communication/Informed_Consent/three_key_elements_2-e. html (accessed 2019 Feb. 13).

2. Canadian Medical Association. Action for safe medical care: 2016 CMPA fact sheet. Ottawa: Canadian Medical Association. Available: https://legacy.cma.ca//Assets/assets-library/document/en/ practice-management-and-wellness/chap-5-e-6.pdf (accessed 2019 Feb. 13).

3. Canadian Medical Protective Association. Shining a light on the medical-legal risks of laparoscopic surgery. CMPA Perspect 2017;9(2):15-18.

4. Pucher PH, Johnston MJ, Archer S, et al. Informing the consent process for surgeons: a survey study of patient preferences, perceptions and risk tolerance. 7 Surg Res 2019;235:298-302.

5. Lyu Y, Cheng Y, Wang B, et al. Early versus delayed laparoscopic cholecystectomy for acute cholecystitis: an up-to-date meta-analysis of randomized control trials. Surg Endosc 2018;32:4728-41.

6. Page AE. Safety in surgery: the role of shared decision-making. Patient Saf Surg 2015;9:24.

7. Uzzaman MM, Tayeh S, Sinha S, et al. Consenting practice for laparoscopic cholecystectomy - Are we doing enough to warn patients about their operation? Int 7 Surg 2011;9:643-7.

8. Canadian Medical Protective Association. Laparoscopic cholecystectomy: We can still be safer. Ottawa: Canadian Medical Protective Association; 2018. Available: www.cmpa-acpm.ca/en/ advice-publications/browse-articles/2018/laparoscopic-cholecystectomywe-can-still-be-safer (accessed 2020 May 10).

9. Kiehl C, Simmenroth-Nayda A, Goerlich Y, et al. Standardized and quality-assured video-recorded examination in undergraduate education: informed consent prior to surgery. 7 Surg Res 2014;191:64-73.

10. Bean S, Magwood B, Abdoh AA, et al. Informed consent: exploring surgical residents' beliefs, attitudes and practices. Healthc $Q$ 2010;13:68-73.

11. Robb A, Etchells E, Cusimano MD, et al. A randomized trial of teaching bioethics to surgical residents. Am f Surg 2005;189:453-7.

12. St John ER, Scott AJ, Irvine TE, et al. Completion of hand-written surgical consent forms is frequently suboptimal and could be improved by using electronically generated, procedure-specific forms. Surgeon 2017;15:190-5.

13. Crozier J, Williams A, Chan STF, et al. Randomized trial of laparoscopic cholecystectomy procedure-specific consent form. ANZ 7 Surg 2018;88:E55-E59.

14. To KB, Cherry-Bukowiec JR, Englesbe MJ, et al. Emergent vs. elective cholecystectomy: conversion rates and outcomes. Surg Infect (Larchmt) 2013;14:512-9.

15. Thompson BM, Sparks RA, Seavey J, et al. Informed consent training improves surgery resident performance in simulated encounters with standardized patients. Am F Surg 2015;210:578-84.

16. Etchells E, Ferrari M, Kiss Al, et al. Informed decision-making in elective major vascular surgery; analysis of 145 surgeon-patient consultations. Can 7 Surg 2011;54:173-8. 